\title{
Analisis Kesantunan Berbahasa dalam Film Animasi Nussa dan Rara Dimanfaatkan sebagai Bahan Ajar Pelajaran Bahasa Indonesia di SMA Kelas XII
}

\author{
Nur Alvi Lael \\ (corresponding author) \\ Program Studi Pendidikan Bahasa dan Sastra Indonesia \\ Universitas Singaperbangsa Karawang \\ Email: 1710631080018@student.unsika.ac.id \\ Oding Supriadi \\ Program Studi Pendidikan Bahasa dan Sastra Indonesia \\ Universitas Singaperbangsa Karawang \\ Email: arjotaruno@gmail.com

\section{Sahlan Mujtaba} \\ Program Studi Pendidikan Bahasa dan Sastra Indonesia \\ Universitas Singaperbangsa Karawang \\ Email: sahlan.mujtaba@fkip.unsika.ac.id
}

\begin{abstract}
APA Citation: Lael, N.A., Supriadi, O., \& Mujtaba, S. (2021). Analisis Kesantunan Berbahasa dalam Film Animasi Nussa dan Rara Dimanfaatkan sebagai Bahan Ajar Pelajaran Bahasa Indonesia di SMA Kelas XII. Silampari Bisa: Jurnal Penelitian Pendidikan Bahasa Indonesia, Daerah, dan Asing, 4(2), 343-357. https://doi.org/10.31540/silamparibisa.v4i2.1329
\end{abstract}

\begin{abstract}
Abstrak
Tujuan penelitian ini adalah untuk mendeskripsikan hasil analisis kesantunan berbahasa film animasi Nussa dan Rara mengenai prinsip kesantunan. Subjek dari penelitian ini yaitu film animasi Nussa dan Rara. Sedangakan, objek dalam penelitian ini yaitu bentuk tuturan yang mengandung kesantunan berbahasa dan menganalisis indikator maksim kesantunan berbahasa yang diduga terdapat pematuhan dan pelanggaran prinsip kesantunan bahasa sesuai yang disampaikan oleh Leech. Jenis penelitian yang digunakan dalam penelitian ini adalah deskriptif kualitatif. Pengumpulan data penelitian ini dilakukan dengan menggunakan metode simak. Teknik simak yang dilakukan yaitu menyimak bahasa yang digunakan oleh penutur untuk diteliti bahasanya, selanjutnya menggunakan teknik lanjutan yaitu teknik simak bebas libat cakap artinya peneliti hanya berperan sebagai pengamat penggunaan bahasa. Hasil penelitian menunjukkan bahwa sebagian besar tuturan yang terdapat dalam film animasi Nussa
\end{abstract}


Nur Alvi Lael, Oding Supriadi, Sahlan Mujtaba

Analisis Kesantunan Berbahasa dalam Film Animasi Nussa dan Rara Dimanfaatkan sebagai Bahan Ajar Pelajaran Bahasa Indonesia di SMA Kelas XII

dan Rara mengandung prinsip kesantunan berbahasa, baik maksim kedermawanan, maksim permufakatan, maksim kebijaksanaan, maksim penghargaan, maksim kesimpatisan, maksim kesederhanaan. Akan tetapi, ada juga 1 tuturan melanggar maksim permufakatan, 2 tuturan yang melanggar maksim kesederhanaan, dan 1 tuturan yang melanggar maksim kedermawanan. Hasil dari analisis film animasi Nussa dan Rara akan dimanfaatkan sebagai bahan ajar di sekolah dalam pembelajaran kesantunan berbahasa SMA kelas XII di kelas peminatan bahasa.

Kata kunci: film animasi Nussa dan Rara, prinsip kesantunan berbahasa, maksim

\title{
Analysis of Language Compliance in the Animation Film Nussa and Rara Used as Teaching Materials for Indonesian Lessons in SMA Class XII
}

\begin{abstract}
The purpose of this study was to describe the results of the analysis of politeness in the language of the animated film Nussa and Rara regarding the principles of politeness. The subject of this research was the animated film Nussa and Rara. Meanwhile, the object in this study is the form of speech that contains language politeness and analyzes the indicators of the maxim of politeness in language which are suspected of having compliance and violating the principles of language politeness as conveyed by Leech. The type of research used in this research is descriptive qualitative. The data collection of this research was carried out using the look method. The listening technique used is listening to the language used by speakers to study the language, then using an advanced technique, namely the free-engage-talk listening technique, meaning that the researcher only acts as an observer of language use. The results showed that most of the speeches contained in the animated film Nussa and Rara contain the principles of politeness in language, both the maxim of generosity, maxim of consensus, maxim of wisdom, maxim of appreciation, maxim of sympathy, maxim of simplicity. However, there is also 1 utterance that violates the maxim of consensus, 2 utterances that violates the maxim of simplicity, and 1 utterance that violates the maxim of generosity. The results of the analysis of the animated film Nussa and Rara will be used as teaching materials in schools in learning politeness in high school language class XII in the language specialization class.
\end{abstract}

Keywords: Nussa and Rara animated film, the principle of politeness in language, maxims

\section{A. Pendahuluan}

Kesantunan berbahasa adalah aturan perilaku yang ditetapkan dan disepakati bersama oleh suatu masyarakat tertentu sehingga kesantunan sekaligus menjadi prasyarat yang disepakati oleh perilaku sosial (Jauhari, 2018; Kurniawati, 2005). Dalam bertutur penutur harus mampu menjaga sikap dan perkataannya supaya berkomunikasi dapat terjaga dengan baik, tanpa menyinggung salah satu penutur. Maka, penting sekali pada saat berkomunikasi untuk menerapkan kesantunan berbahasa.

Nadar (2009:251) dan Chaer (2010) menjelaskan bahwa kesantunan berbahasa yang digunakan penutur bertujuan untuk mengurangi rasa tidak senang,

Silampari Bisa: Jurnal Penelitian Pendidikan Bahasa Indonesia, Daerah, dan Asing Vol. 4, No. 2, 2021 
tidak berkenan hati, atau sakit hati akibat tuturan yang diucapkan penutur. Yang harus diperhatikan penutur dalam berkomunikasi, tidak hanya sekedar mematuhi aturan kerja sama atau demi terjadi kesepahaman, tapi juga perlu saling menghormati tidak merugikan satu sama lain, dan tidak mengancam satu sama lain. Jadi yang diperlukan adalah aturan-aturan selain aturan kerja sama yaitu aturan kesantunan berbahasa atau prinsip kesantunan (Leech, 1993:132).

Brown Levinson (1987) (dalam Basuki, 2015:18) melihat kesantunan berbahasa sebagai'sebuah sistem yang kompleks untuk memperhalus ujaran yang mengancam muka (face threatening act). Kesantunan berbahasa tidak hanya berhubungan dengan pemahaman bagaimana mengucapkan silakan, terima kasih secara tepat, tetapi perlu juga pemahaman nilai budaya suatu masyarakat tutur. Dari beberapa pendapat di atas, penulis menyimpulkan bahwa kesantunan berbahasa adalah kegiatan bertutur dengan ujaran yang baik dan benar berdasarkan kesepakatan penutur dan mitra tutur, serta tidak menyinggung atau melukai lawan bicara dan tidak membuat penuturnya menjadi kehilangan muka saat bertutur.

Menurut Leech (Rahardi, 2015:59) merumuskan kesantunan berbahasa sebagai suatu ujaran dalam prinsip kesantunan yang saling berhubungan. Secara lengkap menurut Leech (1993), prinsip kesantunan didasarkan pada kaidahkaidah. Kaidah-kaidah itu tidak lain adalah bidal-bidal atau pepatah yang berisi nasihat yang harus dipatuhi agar tuturan penutur memenuhi prinsip kesantunan. Secara lengkap Leech (1993) mengemukakan prinsip kesantunan yang meliputi enam maksim berdasarkan submaksimnya akan dipaparkan sebagai berikut.

1) Maksim Kebijaksanaan (Tact Maxim)

Gagasan dasar maksim kebijaksanaan dalam prinsip kesantunan adalah bahwa peserta pertuturan hendaknya berpegang pada prinsip untuk selalu mengurangi keuntungan dirinya sendiri dan memaksimalkan keuntungan pihak lain dalam kegiatan bertutur (Yayuk, 2018).

2) Maksim Kedermawanan (Generosity Maxim)

Dengan maksim kedermawanan atau maksim kemurahhatian, para peserta tuturan diharapkan dapat menghormati orang lain. Penghormatan terhadap orang lain akan terjadi apabila orang dapat mengurangi keuntungan bagi dirinya sendiri dan memaksimalkan keuntungan bagi pihak lain.

3) Maksim Penghargaan (Approbation Maxim)

Di dalam maksim penghargaan dijelaskan bahwa orang akan dapat dianggap santun apabila dalam bertutur selalu berusaha memberikan penghargaan kepada pihak lain. Dengan maksim ini, diharapkan agar peserta pertuturan tidak saling mengejek, saling mencaci, atau saling merendahkan pihak lain.

4) Maksim Kesederhanaan (Modesty Maxim)

Di dalam maksim kesederhanaan atau maksim rendah hati, peserta tutur diharapkan dapat bersikap rendah hati dengan cara mengurangi pujian terhadap dirinya sendiri. Orang akan dikatakan sombong dan congkak hati apabila di dalam kegiatan bertutur selalu memuji dan mengunggulkan dirinya sendiri.

Silampari Bisa: Jurnal Penelitian Pendidikan Bahasa Indonesia, Daerah, dan Asing Vol. 4, No. 2, 2021 
Nur Alvi Lael, Oding Supriadi, Sahlan Mujtaba

Analisis Kesantunan Berbahasa dalam Film Animasi Nussa dan Rara Dimanfaatkan sebagai Bahan Ajar Pelajaran Bahasa Indonesia di SMA Kelas XII

5) Maksim Pemufakatan (Agreement Maxim)

Maksim pemufakatan seringkali disebut dengan maksim kecocokan (Wijana

\& Rohmadi, 2009). Di dalam maksim ini, ditekankan agar peserta tutur dapat saling membina kecocokan atau kemufakatan di dalam kegiatan bertutur. Apabila terdapat kemufakatan atau kecocokan antara diri penutur dan mitra tutur dalam kegiatan bertutur, masing-masing dari mereka akan dapat dikatakan bersikap santun.

6) Maksim Kesimpatisan (Sympath Maxim)

Di dalam maksim kesimpatisan, diharapkan agar perserta tutur dapat memaksimalkan sikap simpati antara pihak yang satu dengan pihak lainnya. Sikap antipati terhadap salah seorang peserta tutur akan dianggap sebagai tindakan tidak santun. Masyarakat tutur Indonesia, sangat menjunjung tinggi rasa kesimpatisan terhadap orang lain ini di dalam komunikasi kesehariannya. Orang yang bersikap antipati terhadap orang lain, apalagi sampai bersikap sinis terhadap pihak lain, akan dianggap sebagai orang yang tidaik tahu sopan santun di dalam masyarakat. Kesimpatisan terhadap pihak lain sering ditunjukan dengan senyuman, anggukan, gandengan tangan, dan sebagainya.

Penelitian mengenai kesantunan berbahasa telah beberapa kali dilakukan. Beberapa diantaranya pernah dilakukan oleh Wulandari (2016) dalam skripsi yang berjudul "Kesantunan Berbahasa pada Acara Mata Najwa di MetroTv" Penelitian ini bertujuan untuk mengidentifikasi tingkat pematuhan bidal-bidal kesantunan pada acara Mata Najwa di MetroTV, mengidentifikasi satuan lingual yang terdapat dalam acara Mata Najwa di MetroTV, dan mengidentifikasi tingkatan kesantunan berbahasa.

Penelitian yang dilakukan oleh Pratama (2019) dalam skripsi yang berjudul "Analisis Kesantunan Berbahasa Guru dan Siswa dalam Pembelajaran Bahasa Indonesia di SMP Negeri 2 Labuapi". Penelitian ini bertujuan untuk mendeskripsikan kesantunan berbahasa yang dilakukan oleh guru dan siswa dalam pembelajaran. Penelitian ini menggunakan pendekatan metodologis yaitu deskriptif kualitatif yang bersifat eksploratif yang menggambarkan keadaan atau status fenomena. Data berupa kata-kata, kalimat dan tuturan Guru dan siswa pada saat pembelajaran.

Penelitian lainnya juga dilakukan oleh Helvianie (2016) dalam skripsi dengan judul "Kesantunan Berbahasa pada Novel Daun yang Jatuh Tak Pernah Membenci Angin Karya Tere Liye". Penelitian ini bertujuan untuk mengidentifikasi wujud kesantunan berbahasa pada novel Daun Yang Jatuh Tak Pernah Membenci Angin karya Tere Liye. Metode yang digunakan dalam penelitian ini adalah metode analisis deskriptif. Teknik analisis data yang digunakan dalam penelitian ini adalah teknik daya pilah pragmatik. Berdasarkan hasil penelitian bahwa semua wujud kesantunan berbahasa yang ditemukan pada novel Daun yang Jatuh Tak Pernah Membenci Angin karya Tere Liye yaitu: (1) memuji lawan bicara, (2) penggunaan kata sapaan, (3) pilihan jawaban, (4) penggunaan kata penanda kesantunan, (5) penggunaan kata maaf dan terima kasih, (6) ketidaklangsungan tuturan, (7)

Silampari Bisa: Jurnal Penelitian Pendidikan Bahasa Indonesia, Daerah, dan Asing Vol. 4, No. 2, 2021 
menyatakan alasan, (8) hubungan timbal balik, serta (9) penggunaan nada bicara dan senyuman.

Oleh karena itu, pentingnya penelitian tentang analisis kesantunan berbahasa dalam film animasi Nussa dan Rara selain belum ada yang meneliti. Harapan dilakukan penelitian ini, yaitu: 1) supaya kasus-kasus mengenai ujaran kebencian dapat menurun angkanya dan masyarakat lebih berhati-hati lagi saat berpendapat; 2) pembahasan mengenai kesantunan berbahasa menjadi lebih luas tentunya dengan melihat fenomena yang terjadi di lingkungan sekitar; 3) serta harapannya siswa bisa menerapkan sikap dan bahasa santun di manapun mereka berada dan dalam lingkungan apapun. Penelitian ini berkaitan dengan pendidikan, yang disesuaikan dengan Program Studi Pendidikan Bahasa dan Sastra Indonesia, Fakultas Keguruan dan IImu Pendidikan.

\section{B. Metode Penelitian}

Penelitian ini menggunakan metode deskriptif kualitatif. Subjek dari penelitian ini yaitu film animasi Nussa dan Rara. Sedangkan, objek dalam penelitian ini yaitu bentuk tuturan yang mengandung kesantunan berbahasa dan menganalisis indikator maksim kesantunan berbahasa yang diduga terdapat pematuhan dan pelanggaran prinsip kesantunan bahasa sesuai yang disampaikan oleh Leech (1993).

Teknik pengumpulan data pada penelitian menggunakan metode simak. Teknik simak yang dilakukan yaitu menyimak bahasa yang digunakan oleh penutur untuk diteliti bahasanya, selanjutnya menggunakan teknik lanjutan yaitu teknik simak bebas libat cakap artinya peneliti hanya berperan sebagai pengamat penggunaan bahasa. Metode ini juga dilengkapi dengan metode catat karena peneliti harus mencatat penggalan setiap tuturan yang diduga memiliki tingkat kesantunan berbahasa yang terdapat dalam film animasi Nussa dan Rara.

Dalam penelitian dengan jenis kualitatif ini peneliti bertindak sebagai pengumpul data dan sebagai instrumen aktif dalam upaya mengumpulkan datadata. Moleong (2010:168) dan Sugiyono (2017) menjelaskan bahwa "peneliti merupakan perencana, pelaksana pengumpulan data, analisis, penafsiran data, dan pada akhirnya peneliti menjadi pelapor atas hasil penelitiannya".

Kehadiran peneliti secara langsung dianggap sebagai penentu keberhasilan untuk memahami kasus yang diteliti, sehingga keterlibatan peneliti secara langsung dengan sumber data mutlak diperlukan. Sebagai instrumen penelitian, maka peneliti juga harus divalidasi sejauh mana peneliti kualitatif siap melakukan penelitian. Validasi terhadap peneliti meliputi pemahaman metode penelitian, penguasaan wawasan terhadap bidang yang diteliti, kesiapan peneliti memasuki objek penelitian baik secara akademik maupun logistik.

\section{Hasil Penelitian dan Pembahasan \\ 1. Hasil Penelitian}

Hasil penelitian berupa data tuturan dikumpulkan dengan cara mengcapture setiap tuturan yang terdapat dalam film animasi Nussa dan Rara yaitu tuturan yang 
diduga mengandung kesantunan berbahasa. Ditemukan data sebanyak 54 tuturan dalam durasi selama 6.34 menit.

Prinsip kesantunan terdiri dari enam maksim yaitu, maksim kebijaksanaan, maksim kedermawanan, maksim penghargaan, maksim kesederhanaan, maksim permufakatan, dan maksim kesimpatisan. Hasil penelitian mengenai prinsip kesantunan yang terdapat dalam film animasi Nussa dan Rara diperoleh hasil data mengenai tuturan yang dipatuhi berdasarkan maksim sebanyak 34 tuturan, sedangkan tuturan yang dilanggar berdasarkan maksim sebanyak 4 tuturan.

\section{Pembahasan}

a. Analisis Kesantunan Berbahasa dalam Film Animasi Nussa dan Rara

Analisis kesantunan berbahasa dalam film animasi Nussa dan Rara yaitu dengan cara menentukan pematuhan dan pelanggaran maksim dari setiap tuturan dalam film animasi Nussa dan Rara. Setelah itu, menentukan fungsi kesantunan yang termasuk ke dalam analisis kalimat.

1. Maksim Kebijaksanaan

Pematuhan

Leech (1993:206) menjelaskan bahwa jika ingin dikatakan maksim kebijaksanaan penutur harus membuat kerugian orang lain sekecil mungkin, dan membuat keuntungan orang lain sebesar mungkin. Pematuhan maksim kebijaksanaan yang terdapat dalam tuturan film animasi Nussa dan Rara (Official, 2020) yaitu:

(13) Rara : "Hah kue cubit juga, masa jualannya sama si".

(14) Nussa: "Ra, jangan begitu kuenya boleh sama tapi kan rasanya berbeda".

Pada tuturan nomor (13), Rara menunjukkan sikap tidak suka saat melihat temannya juga ikut berjualan yang sama dengannya, sehingga Rara berbicara seolah tidak terima temannya ikut berjualan juga di tempat yang sama dengan mereka jualan. Sehingga pada tuturan nomor (14), Nussa mencoba menyadarkan Rara dengan berkata santun dan halus serta menunjukkan sikap yang bijaksana, berdasarkan hal tersebut tuturan nomor (14) merupakan tuturan yang santun dan mematuhi maksim kebijaksanaan.

(17) Abdul : "Wah saingannya berat nih".

(18) Syifa : "Dul rezeki itu udah diatur, jadi jangan khawatir, lagian Nussa dan Rara sahabat kita, jadi gak ada saingan".

Pada tuturan nomor (17), Abdul merasa dagangannya tersaingi oleh temannya sendiri, kemudian ditenangkan oleh Syifa tuturan nomor (18) dengan menggunakan tuturan santun dan tampak dengan jelas bahwa apa yang dituturkan sungguh memaksimalkan keuntungan lawan tuturnya supaya tidak terjerumus pada akhlak yang tercela, dengan cara menenangkan Abdul yang sedang kepanasan karena merasa kalah saingan oleh Nussa dan Rara.

Silampari Bisa: Jurnal Penelitian Pendidikan Bahasa Indonesia, Daerah, dan Asing Vol. 4, No. 2, 2021 
(29) Nussa : "Sebentar yah Pak Ucok, Nussa coba tukerin uangnya dulu".

(30) Pak Ucok : "Ahh pandai sekali kau Nussa".

(31) Nussa : "Dul, Syifa kalian ada uang sepuluh ribuan lima gak?".

Pada tuturan nomor (29) menggunakan tuturan santun. Hal itu ditandai dengan adanya kata "sebentar", karena Nussa tidak langsung bertindak melakukan yang akan dikerjakannya, tetapi Nussa meminta izin terlebih dahulu kepada lawan tuturnya, sehingga tampak dengan jelas bahwa apa yang dituturkan sungguh memaksimalkan keuntungan lawan tuturnya dan menjadikan tuturan tersebut lebih santun. Sedangkan tuturan nomor (31), Nussa menanyakan kepada Syifa mengenai uang, hal ini wajar dilakukan untuk menghilangkan kesalahpahaman bahwa tidak ada saingan di antara mereka, sehingga bertanya adalah cara untuk mencairkan suasana yang sedang panas dan tuturan tersebut tampak mematuhi maksim kebijaksanaan.

(33) Nussa : : :Oh lyah, Pak Ucok kue cubitnya masih kurang kan ya?".

(35) Nussa : : "Nah kebetulan Syifa dan Abdul juga jualan kue cubit".

(36) Pak Ucok : "Naahh cocok sekali itu, uang kembalian belanjaan ku tadi dibelikan kue cubit kalian aja ya".

Pada tuturan nomor (33) dan (35), Nussa menunjukkan sikap yang bijaksana, tampak tuturannya memaksimalkan keuntungan orang lain dan mengurangi keuntungan dirinya sendiri, karena Nussa mempunyai ide bahwa Pak Ucok disuruh untuk membeli kue cubit temannya yaitu Syifa dan Abdul supaya dagangan mereka pun ikut laku. Sedangkan tuturan nomor (36) tuturan yang dilontarkan Pak Ucok merupakan tuturan yang bijaksana karena Pak Ucok mengatakan semua uang kembaliannya untuk dibelikan kue Syifa dan Abdul, sehingga sikaf tersebut mencerminkan sikap yang bijaksana karena memaksimalkan keuntungan terhadap orang lain.

(43) Nussa: "Ra, inget kan pesan Umaa"

(44) Rara : "Inget lah".

(45) Umma: "Kita harus meneladani sikap berdagangnya Rasul, amanah, jujur, dan terpercaya".

Pada tuturan nomor (45), tuturan Umma menunjukan sikap yang bijaksana karena mengajarkan anak-anaknya supaya bersikap jujur saat berdagang, dan memaksimalkan keuntungan.

(48) Rara: "Ka Abdul Ka Syifa maafin Rara yah, karena Rara sudah membuat kaka sebel".

Pada tuturan (48) tuturan yang memaksimalkan keuntungan orang lain karena tuturan tersebut mementingkan keuntungan Abdul dan Syifa meskipun hati

Silampari Bisa: Jurnal Penelitian Pendidikan Bahasa Indonesia, Daerah, dan Asing Vol. 4, No. 2, 2021 
Nur Alvi Lael, Oding Supriadi, Sahlan Mujtaba

Analisis Kesantunan Berbahasa dalam Film Animasi Nussa dan Rara Dimanfaatkan sebagai Bahan Ajar Pelajaran Bahasa Indonesia di SMA Kelas XII

Rara masih sedikit kesal, tetapi demi kebaikan persahabatan mereka, Rara rela meminta maaf kepada Abdul dan Syifa.

\section{Maksim Kedermawanan}

Pematuhan

Dengan maksim kedermawanan atau maksim kemurahan hati, para peserta pertuturan diharapkan dapat menghormati orang lain. Penghormatan terhadap orang lain akan terjadi apabila orang dapat mengurangi keuntungan bagi dirinya sendiri dan memaksimalkan keuntungan bagi pihak lain (Rahardi, 2015:61). Pematuhan maksim kedermawanan yang terdapat dalam tuturan film animasi Nussa dan Rara yaitu:

(1) Rara: "Silahkan dibeli Ibu, ini kue cubit terenak buatan Umma".

Pada tuturan nomor (1) mengandung maksim kedermawanan. Hal ini dibuktikan dengan adanya kata "silahkan", kata tersebut menandakan kalimat santun karena Rara mencoba memberikan penghormatan kepada pelanggan dengan cara berbuat ramah supaya pelanggan tertarik untuk membeli.

(4) Pembeli : "Buat kalian aja kembaliannya saya lagi buru-buru nih".

(5) Nussa : "Makasih ya Bu!".

Pada tuturan nomor (4) terdapat perilaku yang dermawan karena sikap pembeli sangat memaksimalkan keuntungan bagi pihak lain dengan cara memberikan uang kembaliannya kepada Rara dan Nussa. Hal itu menunjukkan maksim kedermawanan karena sikapnya yang murah hati. Sedangkan pada tuturan nomor (5), Nussa dan Rara mencoba bersikap dermawan untuk membalas kebaikan pembeli tersebut dengan mengucapkan terima kasih. Kata "terima kasih" tersebut menunjukkan maksim kedermawanan karena kata yang menunjukkan penghormatan kepada orang lain.

(9) Nussa : "Wiiihh asiik kita jadi ada teman jualan nih Ra".

(10) Rara : "Emang Ka Abdul sama Ka Syifa jualan apa?"

(11) Rara : "Oh agar-agar jeli”.

Pada tuturan nomor (9), terdapat tuturan yang mengandung maksim kedermawanan karena menunjukkan tuturan bahagia sebagai tanda penghormatan kepada temannya Abdul dan Syifa. Tuturan tersebut sangat memaksimalkan keuntungan terhadap orang lain.

(23) Nussa : "Alhamdulillah, ini Pak Ucok kebetulan masih ada tiga bungkus lagi".

(24) Pak Ucok: "Pas banget itu".

(25) Pak Ucok: "Ehhh sayang sekali kalau Cuma hanya tiga bungkus, ahh tapi yah sudah lah, ini uangnya".

Silampari Bisa: Jurnal Penelitian Pendidikan Bahasa Indonesia, Daerah, dan Asing Vol. 4, No. 2, 2021 
Pada tuturan nomor (23), tuturan menunjukkan sikap murah hati sehingga hal itu cocok dengan maksim kedermawanan, karena maksim kedermawanan harus menunjukan perilaku dan tuturan yang murah hati. Hal tersebut ditunjukkan dengan kata "Alhamdulillah" kata tersebut menunjuk pada rasa syukur Nussa karena jualannya telah dibeli oleh Pak Ucok sehingga terdengar lebih santun.

Pada tuturan nomor (25), tuturan yang diucapkan oleh Pak Ucok termasuk dalam tuturan yang mengandung maksim kedermawanan dikarenakan tuturan tersebut sangat memaksimalkan keuntungan terhadap orang lain, sikap Pak Ucok yang tetap membeli dagangan Nussa dan Rara, meskipun tidak sesuai dengan yang dinginkan menunjukan sikap kemurahhatian Pak Ucok terhadap Nussa dan Rara.

(26) Nussa : "Makasih Pak Ucok".

(27) Rara : "Pak Ucok maaf tidak ada kembalian".

(28) Nussa : "Eh tunggu sebentar".

Pada tuturan nomor (26) mengandung maksim kedermawanan karena sikap dan tuturan Nussa yang memberi penghormatan sebagai tanda terima kasih kepada Pak Ucok yang telah memborong semua dagangannya. Pada tuturan nomor (27), mengandung maksim kedermawanan karena tuturan Rara yang mengandung maksim kedermawanan. Hal ini ditunjukkan dengan adanya kata "maaf" dalam tuturannya.

Pada tuturan nomor (28) mengandung tuturan maksim kedermawanan, karena Nussa tidak langsung bertindak, tetapi Nussa bertutur terlebih dahulu seolah-olah memberi jeda kepada Pak Ucok untuk menunggunya sebentar, sehingga tuturan tersebut dikatakan santun, karena apabila Nussa tidak berbicara terlebih dahulu dan langsung saja meninggalkan Pak Ucok sebagai tindakan yang terkesan tidak sopan, sehingga sebagai tanda penghormatan Nussa terhadap Pak Ucok Nussa menyuruh Pak Ucok untuk menunggunya sebentar.

(31) Nussa : "Dul, Syifa kalian ada uang sepuluh ribuan lima gak?".

(32) Syifa : "Sebentar yah Nussa, kayanya ada deh".

Pada tuturan nomor (32) terdapat perilaku yang menunjukkan maksim kedermawanan dengan mengatakan kata "sebentar" tindakan dan tuturan Syifa menunjukan maksim kedermawanan, karena tuturan Syifa merupakan tuturan yang tepat sebagai jawaban dari pertanyaan Nussa, karena Syifa tidak langsung mengatakan secara langsung, dengan tindakan memeriksa terlebih dahulu tindakan tersebut merupakan hal yang santun.

(36) Pak Ucok

(37) Rara

(38) Nussa dan Rara
: "Naahh cocok sekali itu, uang kembalian belanjaan ku tadi dibelikan kue cubit kalian aja ya".

: "Waahhh asyikk".

: "Makasih banyak Pak Ucok".

Silampari Bisa: Jurnal Penelitian Pendidikan Bahasa Indonesia, Daerah, dan Asing Vol. 4, No. 2, 2021 
Nur Alvi Lael, Oding Supriadi, Sahlan Mujtaba

Analisis Kesantunan Berbahasa dalam Film Animasi Nussa dan Rara Dimanfaatkan sebagai Bahan Ajar Pelajaran Bahasa Indonesia di SMA Kelas XII

Pada tuturan nomor (38) mengandung maksim kedermawanan karena tuturan tersebut menandakan suatu penghormatan kepada Pak Ucok dengan mengatakan kata "terima kasih".

(42) Rara : "Ka, ko malah nawarin kue cubitnya ka Abdul sih, kalao kita bilang ke Pak ucok tidak ada kembalian pasti Pak Ucok ngasih sisanya ke kita, kan kita bisa untung banyak".

(43) Nussa : "Ra, inget kan pesan Umaa".

Pada tuturan nomor (43), tuturan mengandung maksim kedermawanan karena sikap atau tuturan Nussa yang bermurah hati mengingatkan adiknya supaya tidak bersikap iri kepada temannya sendiri, sehingga tuturan tersebut mengandung makna memaksimalkan keuntungan terhadap orang lain.

(50) Abdul : : "Karena kalian sudah ngelarisin dagangan kita, ini ada hadiah buat kalian".

(51) Rara : : "Waahh makasih Ka Syifa Ka Abdul".

Pada tuturan nomor (51), mengandung maksim kedermawanan karena tuturan tersebut menandakan suatu penghormatan kepada Syifa dan Abdul dengan mengatakan kata "terima kasih".

(52) Nussa : "Kalian kan jualan nanti kalo di bagikan secara gratis nanti rugi".

(53) Syifa : "Enggak lah, karena berbagi kepada sahabat enggak bakal bikin kita rugi, kita kan jualan bukan hanya mencari untung tapi mencari berkahnya".

Pelanggaran

Pada maksim kedermawanan, Leech (1993:203) mengemukakan, buatlah keuntungan diri sendiri sekecil mungkin, buatlah kerugian diri sebesar mungkin. Jika pematuhan maksim kedermawanan berbunyi seperti itu, maka pelanggaran maksim kedermawanan berkebalikan dengan hakikatnya, yaitu peserta pertuturan memaksimalkan keuntungan bagi diri sendiri dan meminimalkan keuntungan bagi orang lain. yaitu:

Pelanggaran maksim kedermawanan dalam film animasi Nussa dan Rara

(10) Rara: "Emang Ka Abdul sama Ka Syifa jualan apa?".

(11) Rara: "Oh agar-agar jeli".

Pada tuturan nomor (11), mengandung makna yang sangat bertolak belakang dengan maksim kedermawanan, karena Rara berbicara dengan nada yang sinis dan memperlihatkan muka tidak senang sehingga hal itu mengakibatkan

Silampari Bisa: Jurnal Penelitian Pendidikan Bahasa Indonesia, Daerah, dan Asing Vol. 4, No. 2, 2021 
Nur Alvi Lael, Oding Supriadi, Sahlan Mujtaba

Analisis Kesantunan Berbahasa dalam Film Animasi Nussa dan Rara Dimanfaatkan sebagai Bahan Ajar Pelajaran Bahasa Indonesia di SMA Kelas XII

tuturan tidak santun, sehingga dapat menyinggung orang lain yang mendengarnya dan melihatnya.

\section{Maksim Penghargaan}

Pematuhan

Maksim penghargaan Leech mengemukakan para peserta pertuturan selalu berusaha memberikan penghargaan kepada pihak lain. Dengan maksim ini, diharapkan agar para peserta pertuturan tidak saling mengejek, saling mencaci, atau saling merendahkan pihak lain (Rahardi, 2015: 63). Pematuhan maksim penghargaan yang terdapat dalam tuturan film animasi Nussa dan Rara yaitu:

(29) Nussa : : "Sebentar yah Pak Ucok, Nussa coba tukerin uangnya dulu".

(30) Pak Ucok : "Ahh pandai sekali kau Nussa".

Pada saat Pak Ucok tidak mempunyai uang receh untuk membeli kue, sedangkan Nussa dan Rara tidak memiliki uang kembalian maka di situlah Nussa mempunyai ide untuk menukarkan uang Pak Ucok kepada Syifa, dan keluarlah kata pujian yang diucapkan Pak Ucok pada tuturan nomor (30) pada Nussa, dan kata tersebut termasuk dalam maksim penghargaan, karena peserta pertuturan berusaha memberikan penghargaan kepada pihak lain atas idenya.

(49) Syifa : "Gak apa-apa Ra, berdagang memang harus kreatif, sesama pedagang kan harus saling bantu"

(50) Abdul : "Karena kalian sudah ngelarisin dagangan kita, ini ada hadiah buat kalian".

Setelah Nussa membantu Abdul dan Syifa melariskan dagangannya, Syifa dan Abdul mencoba membalas kebaikan Nussa dan Rara dengan memberikannya sisa kue cubitnya. Jadi, melalui tindakan dan tuturan nomor (50) tersebut termasuk dalam maksim penghargaan karena Syifa dan Abdul memberikan penghargaan kepada Nussa dan Rara yang telah membantunya melariskan dagangannya sehingga tidak ada lagi persaingan ataupun saling membenci diantara mereka.

\section{Pelanggaran}

Jika dalam maksim penghargaan peserta tutur menghindari sikap saling mengejek, saling mencaci, atau saling merendahkan pihak lain. Sehingga jika peserta tutur yang sering mengejek peserta tutur lain di dalam kegiatan bertutur akan dikatakan sebagai seorang yang tidak sopan, karena tindakan mengejek merupakan tindakan tidak menghargai orang lain. Tuturan dalam film animasi Nussa dan Rara tidak mengandung pelanggaran terhadap maksim penghargaan, karena tidak adanya sikap saling mengejek satu sama lain. 
Nur Alvi Lael, Oding Supriadi, Sahlan Mujtaba

Analisis Kesantunan Berbahasa dalam Film Animasi Nussa dan Rara Dimanfaatkan sebagai Bahan Ajar Pelajaran Bahasa Indonesia di SMA Kelas XII

\section{Maksim Kesederhanaan}

Pematuhan

Pada maksim ini Leech (1993) mengungkapkan tuturan akan santun jika peserta pertuturan mengurangi pujiannya pada dirinya sendiri, dan menambah cacian pada diri sendiri. Maksim ini sering disebut maksim kerendahan hati, peserta tutur diharapkan dapat bersikaf rendah hati dengan cara mengurangi pujian terhadap dirinya sendiri.

Tuturan yang mengandung maksim kesederhanaan yang tedapat dalam film animasi Nussa dan Rara adalah sebagai berikut:

(50) Abdul : "Karena kalian sudah ngelarisin dagangan kita, ini ada hadiah buat kalian".

(51) Rara : "Waahh makasih Ka Syifa Ka Abdul".

(52) Nussa : "Kalian kan jualan nanti kalo di bagikan secara gratis nanti rugi".

(53) Syifa : "Enggak lah, karena berbagi kepada sahabat enggak bakal bikin kita rugi, kita kan jualan bukan hanya mencari untung tapi mencari berkahnya".

Pelanggaran

Dapat dikatakan melanggar maksim kesederhanaan jika seseorang dikatakan sombong dan congkak hati, di dalam kegiatan bertutur selalu memuji dan mengunggulkan dirinya sendiri.

(15) Rara: "Enakkan juga kue cubit Umma".

(16) Rara: "Ka, dagangannya Ka Abdul sama Ka Syifa masih banyak".

Pada tuturan nomor (15) dan (16) merupakan tuturan yang melanggar maksim kesederhanaan. Hal ini terlihat pada perkataan Rara karena dia bersikap sombong dengan mengucapkan bahwa kuenya lah yang paling enak, sehingga kue temannya Abdul dan Syifa tidak laku. Pelanggaran tersebut terlihat saat Rara memuji dan mengunggulkan kue jualan miliknya.

\section{Maksim Permufakatan}

Pematuhan

Di dalam maksim ini agar penutur dapat saling membina kecocokan atau kemufakatan di dalam kegiatan bertutur. Apabila terdapat kemufakatan atau kecocokan antara diri penutur dan mitra tutur dalam kegiatan bertutur, masingmasing dari mereka akan dapat dikatakan bersikap santun.

Tuturan yang mengandung maksim permufakatan yang terdapat dalam film animasi Nussa dan Rara adalah sebagai berikut:

(35) Nussa : "Nah kebetulan Syifa dan Abdul juga jualan kue cubit".

(36) Pak Ucok : "Naahh cocok sekali itu, uang kembalian belanjaan ku tadi dibelikan kue cubit kalian aja ya".

Pada percakapan nomor (36), yang dituturkan oleh pak ucok mengandung maksim permufakatan, karena pak ucok merasa setuju atas saran yang diberikan

Silampari Bisa: Jurnal Penelitian Pendidikan Bahasa Indonesia, Daerah, dan Asing Vol. 4, No. 2, 2021 
Nur Alvi Lael, Oding Supriadi, Sahlan Mujtaba

Analisis Kesantunan Berbahasa dalam Film Animasi Nussa dan Rara Dimanfaatkan sebagai Bahan Ajar Pelajaran Bahasa Indonesia di SMA Kelas XII

oleh Nussa, Pak ucok menerima saran tersebut dengan senang hati tanpa menyinggung perasaan lawan tuturnya, maka pada tuturan nomor (36) merupakan pematuhan terhadap maksim permufakatan.

\section{Pelanggaran}

Terdapat pelanggaran terhadap maksim permufakatan yaitu berupa perilaku penutur yang memperlihatkan sikap tidak senang terhadap lawan tutur. Tuturan yang melanggar maksim permufakatan yang terdapat dalam film animasi Nussa dan Rara adalah sebagai berikut:

(12) Abdul: "Dan satu lagi Taraaaa, ini kue cubit coklat lumer".

(13) Rara : "Hah kue cubit juga, masa jualannya sama si".

Pada tuturan nomor (13) memperlihatkan bahwa adanya perilaku yang tidak setuju, sehingga hal itu dapat menimbulkan perilaku tidak santun dan dapat melukai hati lawan tutur. Maka tuturan nomor (13) merupakan tuturan yang melanggar maksim permufakatan.

\section{Maksim Kesimpatisan}

Pematuhan

Di dalam maksim kesimpatisan, diharapkan agar peserta tutur dapat memaksimalkan sikap simpati antara pihak yang satu dengan pihak yang lainnya. Tuturan yang mematuhi maksim kesimpatisan dalam film animasi Nussa dan Rara dalah sebagai berikut:

(49) Nussa: "Gak apa-apa Ra, berdagang memang harus kreatif, sesama pedagang kan harus saling bantu".

Dalam tuturan nomor (49) merupakan tuturan yang mematuhi maksim kesimpatisan karena tuturan tersebut ditunjukkan dengan senyuman dan gandengan tangan terhadap Rara, karena pada saat itu Nussa sedang menasihati Rara supaya jangan bersikap iri terhadap temannya sendiri sehingga dengan adanya sikap yang ditunjukan tersebut tuturan nomor (49) dikatakan santun.

\section{Pelanggaran}

Dalam maksim kesimpatisan tidak ditemukan tuturan yang mengandung pelanggaran terhadap maksim kesimpatisan.

\section{b. Pemanfaatan Hasil Analisi Kesantunan Berbahasa Film Animasi Nussa dan \\ Rara sebagai Bahan Ajar Pendidikan Karakter}

Penulis memanfaatkan hasil dari penelitian analisis kesantunan berbahasa film animasi Nussa dan Rara sebagai bahan ajar yang digunakan oleh guru pada pembelajaran kesantunan berbahasa di kelas peminatan bahasa Indonesia kelas XII SMA. Bahan ajar ini penulis sajikan ke dalam bentuk bahan ajar pandang dengar dengan berpedoman pada pencapaian kompetensi dan indikator 
Nur Alvi Lael, Oding Supriadi, Sahlan Mujtaba

Analisis Kesantunan Berbahasa dalam Film Animasi Nussa dan Rara Dimanfaatkan sebagai Bahan Ajar Pelajaran Bahasa Indonesia di SMA Kelas XII

pembelajaran kesantunan berbahasa. Adapun kompetensi dasar yang harus terpenuhi yaitu: (1) memahami prinsip kesantunan berbahasa dalam interaksi sosial, dan (2) mengabstraksi prinsip kesantunan berbahasa dalam interaksi sosial. Hasil analisis ini nantinya akan menjadi pelengkap dalam pemebelajaran kesantunan berbahasa, dan juga pembelajaran pendidikan karakter yang diintegrasikan terhadap pembelajaran bahasa Indonesia SMA kelas XII.

\section{Simpulan dan Saran}

Berdasarkan hasil penelitian, keseluruhan film animasi Nussa dan Rara yang telah penulis teliti, terdapat tuturan yang mematuhi prinsip kesantunan yaitu sebanyak 34 tuturan, 13 tuturan yang mematuhi maksim kedermawanan, 8 tuturan yang mematuhi maksim permufakatan, 7 tuturan yang mematuhi maksim kebijaksanaan, 1 tuturan yang mematuhi maksim penghargaan, 1 tuturan yang mematuhi maksim kesimpatisan, 4 tuturan yang mengandung maksim kesederhanaan. Sedangkan tuturan yang melanggar terhadap prinsip kesantunan sebanyak 4 tuturan. Diantaranya 1 tuturan yang melanggar maksim permufakatan, 2 tuturan yang melanggar maksim kesederhanaan, 1 tuturan yang melanggar maksim kedermawanan, tidak ditemukannya pelanggaran atas maksim kebijaksaan, kesimpatisan, dan penghargaan. Penelitian ini berkaitan dengan pendidikan, yang disesuaikan dengan program studi penulis yaitu Pendidikan Bahasa dan Sastra Indonesia Fakultas Keguruan dan Ilmu Pendidikan. Hasil dari analisis film animasi Nussa dan Rara akan dimanfaatkan sebagai bahan ajar di sekolah dalam pembelajaran kesantunan berbahasa SMA kelas XII di kelas peminatan bahasa.

\section{Daftar Pustaka}

Basuki, R. (2015). Kesantunan Berbahasa dalam Wacana Interaksi Komunikasi di Lingkungan Universitas Bengkulu. BAHTERA : Jurnal Pendidikan Bahasa dan Sastra, 14(1), 16 - 25. https://doi.org/10.21009/BAHTERA.141.02

Chaer, A. (2010). Kesantunan Berbahasa. Jakarta: Rineka Cipta.

Helvianie, W. (2016). "Kesantunan Berbahasa pada Novel Daun yang Jatuh Tak Pernah Membenci Angin Karya Tere Liye”. Skripsi. Palembang: Universitas Sriwijaya.

Jauhari, A. (2018). Realisasi Kesantunan Berbahasa dalam Proses Belajar Mengajar Bahasa Indonesia Kelas XI SMK Realisasi. Diksi, 25(1). doi:10.21831/diksi.v25i1.18851

Kurniawati, E. (2005). "Kesantunan Berbahasa dalam Film Kartun Shincan dan Doraemon”. Skripsi. Semarang: Unnes.

Silampari Bisa: Jurnal Penelitian Pendidikan Bahasa Indonesia, Daerah, dan Asing Vol. 4, No. 2, 2021 
Nur Alvi Lael, Oding Supriadi, Sahlan Mujtaba

Analisis Kesantunan Berbahasa dalam Film Animasi Nussa dan Rara Dimanfaatkan sebagai

Bahan Ajar Pelajaran Bahasa Indonesia di SMA Kelas XII

Leech, G. (1993). Prinsip-Prinsip Pragmatik (Edisi Terjemahan oleh M. D. D.Oka). Jakarta: Universitas Indonesia Press.

Moleong, L. J. (2010). Metodologi Penelitian Kualitatif. Bandung: PT. Remaja Rosdakarya.

Nadar, F.X. (2009). Pragmatik dan Penelitian Pragmatik. Yogyakarta: Graha IImu.

Official, Nussa. (2020). Nussa: Chef Rarra. Youtube: Official Nussa. https://www.youtube.com/watch?v=6eyXM45wC6Q

Pratama, D.H.P. (2019). "Analisis Kesantunan Berbahasa Guru dan Siswa dalam Pembelajaran Bahasa Indonesia di SMP Negeri 2 Labuapi". Skripsi. Mataram: Universitas Muhammadiyah Mataram. https://repository.ummat.ac.id/554/

Rahardi, R. K. (2015). Pragmatik Kesantunan Imperatif Bahasa Indonesia. Jakarta: Erlangga.

Sugiyono. (2017). Metode Penelitian Kuantitatif, Kualitatif, dan R\&D. Bandung: Alfabeta.

Wijana, I.D.P. \& Rohmadi, M. (2009). Analisis Wacana Pragmatik: Kajian Teori dan Analisis. Surakarta: Yuma Pustaka.

Wulandari, R. (2016). Kesantunan Berbahasa pada Acara Mata Najwa di MetroTV. Skripsi. Universitas Negeri Semarang.

Yayuk, R. (2018). Realisasi Pelanggaran Maksim Kebijaksanaan dalam Tuturan Manyaru Bahasa Banjar. Sirok Bastra, 5(1). doi:10.37671/sb.v5i1.95

Silampari Bisa: Jurnal Penelitian Pendidikan Bahasa Indonesia, Daerah, dan Asing Vol. 4, No. 2, 2021 